\title{
Sustainability of the rice-shrimp farming system in Mekong Delta, Vietnam: a climate adaptive model
}

\author{
Huy Duc Dang \\ Faculty of Economics, Nong Lam University, Ho Chi Minh, Vietnam
}

\begin{abstract}
Purpose - Agricultural systems in Mekong Delta have transformed to cope with climate change. Various researches pointed out that integrated agriculture-aquaculture (IAA) farming systems (i.e., rice-shrimp, ricefish. ..) emerged as potential climate adaptive practices. However, limited studies are attempting to assess the sustainability of these agricultural practices. Therefore, it is essential to assess whether or not these systems will be sustainable in the context of climate change and what can be done to make it sustainable. The present study conducted the sustainability assessment of the rice-shrimp system to identify potential areas for improvement as well as policy implication to increase resilience and adaptation of coastal IAA system which could contribute to the understanding of other coastal agricultural deltas around the globe.

Design/methodology/approach - This study used a quantitative approach including the assessment protocol of van Asselt et al. (2014), the assessment framework of Vanloon et al. (2005), and the MCA methodology to flexibly and holistically assess the sustainability level of agricultural systems.

Findings - Results concluded that rice-shrimp systems have the potential to improve livelihood, food security, and adaptation of coastal farmers. Major improvements should be considered for productivity, efficiency, and equity themes, while minor improvements can be made for stability, durability, and compatibility themes.

Originality/value - This research could be used as a guideline for sustainability assessment in a contextspecific case study of IAA, which showed a potential for the application of other climate-smart IAAs in similar contexts around the globe.
\end{abstract}

Keywords Sustainability assessment, Multiple criteria analysis, Climate change, Integrated farming system Paper type Research paper

\section{Introduction}

Back in the early 1990s, in Mekong Delta, rice culture dominated farming activities in terms of meeting subsistence needs, and other livelihood alternatives including aquaculture, fruit production, and livestock were trivial (Nhan et al, 2007). Since 1999, the Vietnamese government has promoted diversification in agriculture by increasing the contribution of aquaculture, while shrinking down the proportion of rice in the total agriculture production output (Luu, 2002).

From 2010 to 2017, aquaculture in Ben Tre province grew faster than both fisheries and rice paddy as a whole (GSO, 2017). In the same period, the growth rate of aquaculture production was approximately 54 percent, while that of fisheries was approximately 43 percent. The production of rice paddy decreased by 34 percent, giving room to aquaculture by following the aim of the province. Integrated agriculture-aquaculture systems (IAA) were

\section{JEL Classification - O13, O47, Q01, Q54}

(C) Huy Duc Dang. Published in Journal of Economics and Development. Published by Emerald Publishing Limited. This article is published under the Creative Commons Attribution (CC BY 4.0) licence. Anyone may reproduce, distribute, translate and create derivative works of this article (for both commercial and non-commercial purposes), subject to full attribution to the original publication and authors. The full terms of this licence may be seen at $\mathrm{http}$ ://creativecommons.org/licences/by/4.0/legalcode

The author gratefully acknowledged the help of local authorities, 58 farmers, 2 local agricultural-fishery extensionists in facilitating the collection of information, survey, and field observation. I also would like to thank all experts from Nong Lam University for their guidance and consultation, and also anonymous reviewers who provided insightful comments to improve the manuscript of the study.

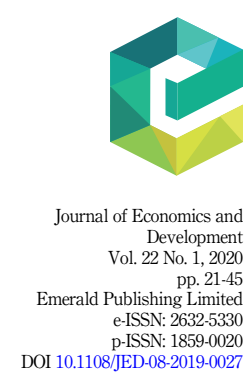

Received 31 August 2019

Revised 22 October 2019 4 November 2019

Accepted 5 November 2019 adaptive model 
JED

22,1

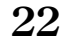

widespread and contributed to the diversification theme of local development (Nhan et al., 2007; Nguyen et al., 2016). IAA farming came in various combinations between fish, shrimp or prawn, livestock, and rice cultivation on the same field. Among them, rice-fish and rice-shrimp are being promoted in research areas by local authority as a sustainable way to improve the livelihood of local farmers. Unfortunately, there was obvious evidence that signaled an unsustainable development of farming in the coastal area of Ben Tre. One of the reasons was the severe saline intrusion into groundwater and surface water in the Mekong Delta due to the increasing sea levels, which made Ben Tre one of the most vulnerable coastal areas (World Bank, 2010; Renaud et al., 2015; GSO, 2016). The impact of increased sea levels also included soil loss, inundation, drought, erosion, and desertification (IMHEN, 2010), which could hamper or threaten the development of coastal agro-ecosystems. Indeed, GSO (2017) reported an earlier flood in the Mekong River Delta impacted the cultivation progress, areas, and crop productivity. Unsurprisingly, in the report on the integration of land use plan for 2018, People Committee of Thanh Phu District (2018) proclaimed that the entire groundwater in Thanh Phu District was salinized with excessive mineral levels prescribed for a human. Besides, MARD (2016) concluded that changes in upstream damn operations from countries such as China, Thailand, and Cambodia resulted in unqualified river water with low alluvium or sediment loads. For the mentioned reasons, the role of IAA became more critical to the adaptation of climate change in coastal areas. However, climate change is challenging IAA farming with more severe drought, flood fluctuations, increased environmental temperatures, and unusual weather; as a result, along with low water level, the increase in water temperature is jeopardizing the sustainability of aquaculture (Leigh et al., 2017; Quach et al., 2017; Poelma, 2018). Moreover, IAA farming requires knowledge and proper techniques to produce more efficiently and effectively, especially for brackish IAAs, which farmers lacked (Loc et al., 2017; Poelma, 2018). Furthermore, other environmental stresses, such as cross-infection from intensive aquaculture, could also pose threats to IAA farming. Overall, the sustainable growth of IAA in the context of unpredictable climate changes remained a puzzle to the authority to accomplish resilient agro-ecosystems. Very few studies successfully addressed the problem.

This study aimed at investigating the sustainability of rice-shrimp, the most popular IAA farming system in the study area, to determine how farmers can adapt to climate change, and to recommend possible adaptations, if any, for current farming practices. We conducted both top-down and bottom-up approaches to shed light on the current IAA farming system to identify potential areas for improvement, as well as policy implications to increase resilience and adaptation of coastal IAA systems, which could contribute to the understanding of other coastal agricultural deltas around the globe.

\section{Data and methodology}

\subsection{Case study background}

2.1.1 Study area. Ben Tre province was the first out of the top ten provinces of Mekong Delta inundated by $1 \mathrm{~m}$ sea-level rise, of which approximately 50 percent of the total area was flooded (World Bank, 2010). Chosen research locations were Thanh Phu and Binh Dai commune of Ben Tre province (Figure 1), which were the most vulnerable coastal areas in Ben Tre, with the highest level of poverty (MARD., 2016). People in the area relied heavily on agriculture for their livelihoods, especially in rice culture and recently in IAA farming, adapting to climate change, in particular integrated shrimp cultivation. Indeed, Nguyen et al. (2016) suggested that shrimp production helped to alleviate poverty. Moreover, as income increases, the role of aquaculture will be increasingly substantial. The link between IAA farming and poverty alleviation signaled the need for sustainability assessment, especially the rice-shrimp model.

2.1.2 Description of the rice-shrimp farming system. The rice-shrimp culture is an ancient and traditional practice that farmers developed using their resources, and has drawn 


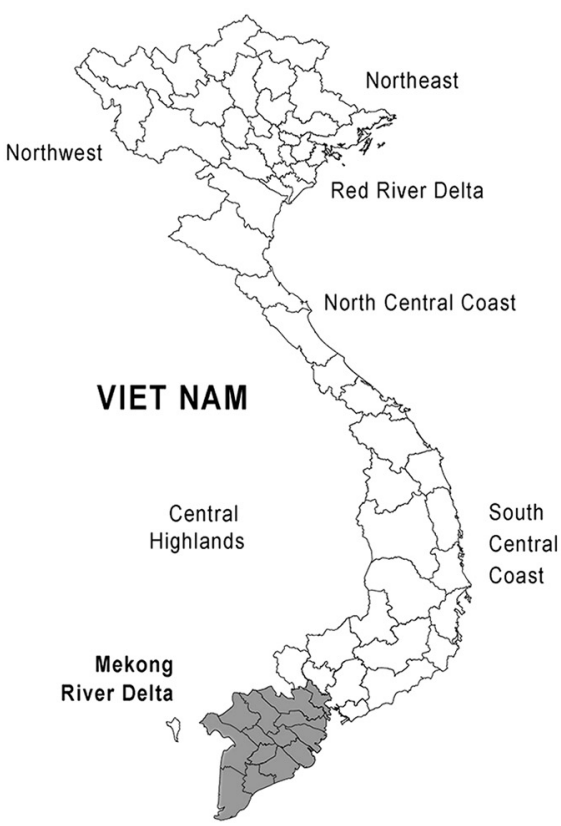

\section{Source(s): Authors own elaboration}

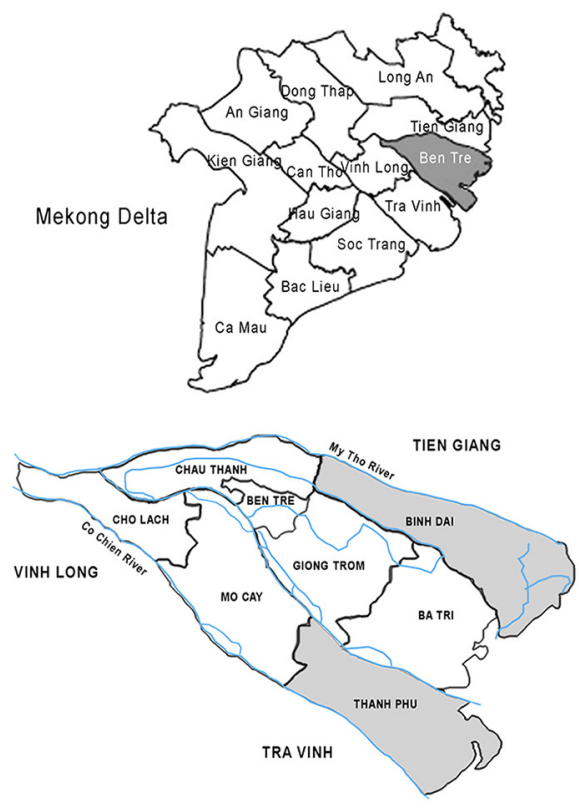

Study area of Binh Dai and Thanh Phu District, Ben Tre province, Vietnam

attention from the Vietnamese government as a solution for poverty alleviation of impoverished farmers. Due to the widespread of hatcheries in Vietnam, shrimp cultivation has shifted from wild-caught, juvenile shrimp post-larvae from sluice gates into farms with the help of tides, to acquiring quality-controlled seeds from hatcheries, making the riceshrimp culture more intensified (Phuong et al., 2006) (See Figure 2).

According to Phuong et al. (2006), there are two main forms of rice-shrimp farming: alternate culture model (rotational culture), and integrated culture model (simultaneous culture). Farmers' selection of models depends on their preferences or typical characteristics of the farm. Due to the saline intrusion nature of the research area, most farmers in the area opted for a mixed practice between rotational and simultaneous models. Figure 3 shows the difference in the application of rice-shrimp farming of Ben Tre apart from other provinces in the Mekong Delta (i.e., Vinh Long, Tra Vinh, Can Tho, An Giang, and Dong Thap). In Ben Tre, rice-shrimp culture was employed during the wet season between September and December, and mono-shrimp during the dry season between March and July. In the mixed culture (or as well as simultaneous culture), the rice paddies must be redesigned to adapt to shrimp stocking. In Binh Dai, the surrounding trench is built with a depth of $1.36 \pm 0.94 \mathrm{~m}$, and a width of $5.02 \pm 2.59 \mathrm{~m}$, and that in Thanh $\mathrm{Phu}$, it is $1.35 \pm 1.00 \mathrm{~m}$ in depth, and $4.73 \pm 2.26 \mathrm{~m}$ in width (see illustrations in Figure 2) along the dike. The total rice farming area of Binh Dai and Thanh Phu is $6,530 \pm 4,120 \mathrm{~m}^{2}$ and $6,060 \pm 4,020 \mathrm{~m}^{2}$, respectively. Regarding the total surface water area for shrimp farming, Binh Dai has a slightly larger area of $10,140 \pm 7,300 \mathrm{~m}^{2}$ than $9,620 \pm 7,050 \mathrm{~m}^{2}$ of Thanh Phu. During the wet season, rainfall plus the inflow of water from the river helped to flush residual salt from rice fields. Thus, rice-shrimp simultaneous culture was performed. In July, farmers release shrimp seeds into the ditch which provides the refuge for shrimps (M. rosenbergii) from the beginning to the rice harvest period (Figure 2a). After the rice is harvested, in December, farmers will provide an influx of water to allow shrimps to 


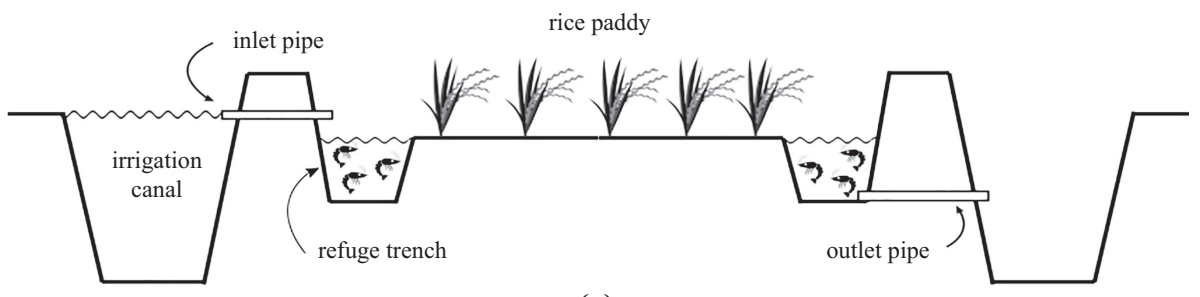

(a)

\section{Figure 2.}

Rice-shrimp farming system. Shrimp shelter in the side trench during rice cultivation (a). After rice harvesting, farmers will open the inlet pipe to flood the field to allow shrimps to eat the leftovers on the rice field (b)

\section{Figure 3.}

The application of riceshrimp farming in the Mekong Delta included the current application in Ben Tre province (mixed culture).

Periods of shrimp culture are indicated by solid arrows, while periods of rice cultivation are indicated by a dotted arrow. In the integrated culture, the short and heavy dotted arrow indicates the nursing culture

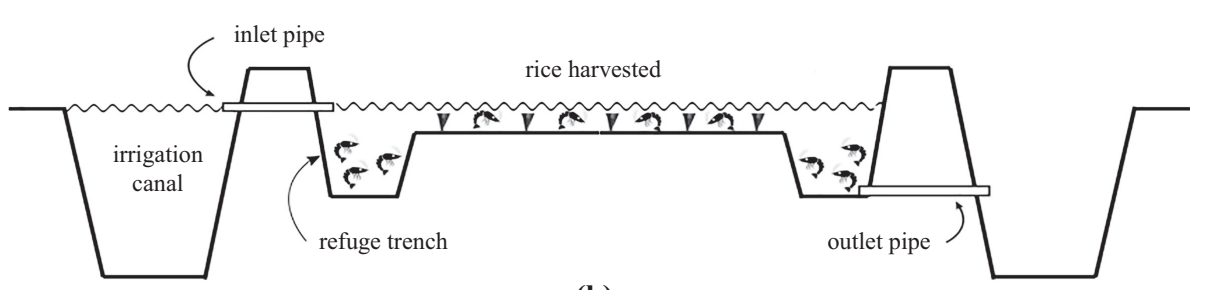

(b)

\begin{tabular}{|c|c|c|c|c|c|c|c|c|c|c|c|c|}
\hline Month & 3 & 4 & 5 & 6 & 7 & 8 & 9 & 10 & 11 & \multirow{2}{*}{\multicolumn{3}{|c|}{\begin{tabular}{c|c|c}
12 & 1 & 2 \\
\multicolumn{2}{|c|}{ Winter-spring rice }
\end{tabular}}} \\
\hline & \multicolumn{9}{|c|}{ Summer-autumn rice } & & & \\
\hline $\begin{array}{l}\text { Integrated } \\
\text { Culture }\end{array}$ & & - & & & & & & & & & & \\
\hline $\begin{array}{l}\text { Alternate } \\
\text { Culture: } \\
\text { Type } 1\end{array}$ & & & & & & & & & & & & \\
\hline $\begin{array}{l}\text { Alternate } \\
\text { Culture: } \\
\text { Type } 2\end{array}$ & & & & & & & & & & & & \\
\hline $\begin{array}{l}\text { Mixed } \\
\text { Culture }\end{array}$ & & & & & & & & & & & & \\
\hline
\end{tabular}

Source(s): Adapted and modified from Phuong et al. (2006) for Ben Tre province

eat the leftover by-products of the rice paddy (Figure 2b). For this model, farmers reported low shrimp productivity due to the small size of harvested shrimps and low survival rates because of trash fish predation.

During the dry season, in March, farmers open the flap gate to allow saline water to flood the field to perform the alternate shrimp culture. The tiger shrimp post-larvae (or P. monodon) or sometimes white-legged (or L. vannamei) is released at a quite high stocking density of $11.11 \pm 5.97$ and $10.31 \pm 4.96$ post-larvae per square meter for Binh Dai and Thanh Phu, respectively. Low survival rates of shrimps because of trash fish predation result in additional batches of complementary post-larvae, around $1.76 \pm 0.82$ and $1.67 \pm 0.77$, being released for Binh Dai and Thanh Phu.

It should be noted that different rice-shrimp settings were employed by farmers in other areas. For example, Phuong et al. (2006) reported different applications of rice-shrimp farming 
such as the integrated culture observed in Vinh Long and Tra Vinh provinces, while alternate culture-Type 1 and Type 2 were found in Can Tho, An Giang, and Dong Thap provinces. However, this study only focused on the described practice above, as it is dominant and could A climate also contribute to the common understanding regarding the subject matter.

\subsection{Conceptual framework}

The World Commission on Environment and Development developed the first guiding principles for sustainable development as "development which meets the present needs without compromising the ability of future generations to meet their own needs" (WCED, 1987). The scientific community generally agreed that sustainable agriculture must sufficiently address multidimensional aspects including economic, social, and environmental objectives. Since then, countless methods have been introduced to access agricultural sustainability; nevertheless, predominant approaches were in favor of indicatorbased frameworks (OECD, 2001; Ness et al., 2007). Despite numerous indicator-based frameworks being proposed, there is no "one size fits all" assessment tool. Salient issues arose, associating with the selection of the right framework for the right case study. Compatibility remained one of the essential critera for framework selection (De Mey et al., 2011; Marchand et al., 2014). The compatibility characteristic of a tool is somehow reflected through the role of context-specificity. A generic sustainability assessment framework can successfully address issues related to the environmental dimension; however, it is unable to explain context-specific issues regarding economic and social dimensions (Gasso et al., 2015). Thus, this study first developed a set of guiding principles for framework selection. Due to the aim and scope of the study (Table I) and following Marchand et al. (2014), we agreed that the selected framework should:

(1) Fit the aim and scope of the study (Table I).

(2) Be simple but sufficient enough to promote a systematic and structured sustainability assessment.

(3) Have available and correct input data for processing.

(4) Be transparent in assessment phases (calculation, weighing, and aggregation).

(5) Be compatible with existing data systems and local conditions.

(6) Be relevant to use and implement by end-users (i.e., farmers, local authority) (effectiveness).

For the mentioned criteria, the assessment framework of Vanloon et al. (2005) was found appropriate for this study, as used in a similar study of Talukder et al. (2016), which successfully accessed sustainability of farming systems in the coastal area of Bangladesh.

\begin{tabular}{|c|c|c|c|c|c|c|}
\hline Criteria & $\begin{array}{l}\text { Primary } \\
\text { purpose }\end{array}$ & $\begin{array}{l}\text { Level of } \\
\text { assessment }\end{array}$ & $\begin{array}{l}\text { Geographical } \\
\text { scope }\end{array}$ & Sector scope & Thematic scope & $\begin{array}{l}\text { Perspective on } \\
\text { sustainability }\end{array}$ \\
\hline Classes & $\begin{array}{l}\text { - Research } \\
\text { - Policy } \\
\text { advice } \\
\text { - Farm } \\
\text { advice }\end{array}$ & - Region & $\begin{array}{l}\text { - Applicable } \\
\text { globally to } \\
\text { coastal } \\
\text { delta areas }\end{array}$ & $\begin{array}{l}\text { - Applicable } \\
\text { to } \\
\text { IAA farming } \\
\text { systems }\end{array}$ & $\begin{array}{l}\text { - Economic } \\
\text { - Social } \\
\text { - Environmental }\end{array}$ & $\begin{array}{l}\text { - Mixed } \\
\text { perspective } \\
\text { (Farm \& } \\
\text { societal } \\
\text { perspectives) }\end{array}$ \\
\hline
\end{tabular}

Source(s): Author's own inference based on (Norman et al., 1998; Marchand et al., 2014)

Table I.

Aims and scopes of the sustainability assessment of the riceshrimp integrated farming model 
JED

22,1

The framework partitioned various dimensions of sustainability into six areas: productivity, stability, efficiency, durability, compatibility, and equity. According to Vanloon et al. (2005), six sustainability categories can be distinguished and defined as follows:

Productivity. Any sustainable agricultural systems must be capable of producing high yields to meet the needs of the farm family as well as to contribute to the global food requirements.

Stability. The high level of productivity must be maintained over an extended period. Generally, stability cannot be measured directly, but indirectly via the quality of the resources on which production depends.

Efficiency. In the process of crop production, various resources are required-human, animal, and material — and should be used at their highest potentials to maximize outputs. So, this indicator can be measured in various ways and also be expressed in financial terms.

Durability. Any farming process is often subjected to various stresses (i.e., water, pest). Hence, durability measures whether or not the sustainable system is intrinsically resilient in the presence of such stresses.

Compatibility. In common sense, compatibility implies the ability of an agricultural system to fit in with the surrounding human, social, and natural environments, and at the same time sustain and enhance them. The nature of farming is beneficial to human wellbeing, but at the same time detrimental to the environment, such as water contamination, loss of biodiversity, or other the collapse of collaborative ecosystems. Therefore, compatibility refers to harmony among all dimensions of sustainability.

Equity. Agriculture should promote a good quality of life among various individuals involved in farming activities and within families. This refers to the consideration for the standard of living, health, and education as well as social welfare for all people in a specific community. Relating to SAFA framework, FAO (2014), this category likely covers economic and social aspects of sustainability, which collaboratively reflects the quality of life.

Often, measuring sustainability performance requires technical data, such as soil nutrients and chemicals. These data were scarce due to finances and time constraints. For that reason, multi-criteria analysis (MCA) was employed as a solution to this problem (criterion 3). To further clarify the transparency of the assessment (criterion 5), this research followed the sustainability evaluating protocol of van Asselt et al. (2014). By combining qualitative and quantitative approaches, this study expected a more comprehensive result due to the inclusion of all related indicators, which might be bypassed in the case of data unavailability.

2.2.1 Sustainability assessment protocol. The sustainability assessment was consulted by a group of five experts from Nong Lam University. They were also independent research members of a climate change adaptation project in the Mekong Delta. Experts are specialized in a wide range of related disciplines covering all three dimensions of sustainability, namely, economic, social, and environmental. Due to objective reasons, it was difficult to involve a governmental official. Thus, an expert in coastal agriculture was set out to play a role as a policymaker. Note that, he worked closely with the local authority in numerous past projects. Therefore, he was responsible for policy-related consultation. According to the assessment protocol of van Asselt et al. (2014), after defining the case study with the involvement of researchers and policymakers guided by a set of four criteria (i.e., measurability, sensitivity, case, and theme relevant), the gross list of indicators will then again be assessed based on additional five filtering criteria (i.e., min indicators per dimension, indicator for profitability, indicator for societal support, indicator coverage, data availability) to establish the core list of indicators with the assistance of literature and expert opinions. To further employ the bottom-up approach, the author also invited two extension agents, who were also rice-shrimp farmers, to explore their knowledge in the local context to merge with expert opinions for the final decision regarding the core list of indicators. At the evaluation step, researchers and 
policymakers both engage to assess whether or not adjustment was needed and to constitute sustainability limits taking reference from the vast body of literature and indigenous knowledge from the local context. Afterward, experts also advised on the collection of data, relying on the current setting of the assessment and also upon a strong base of literature. It is worth noting that farmers in this step play a role as information providers, but not assessors. Particularly in this study, the author ignored the last step of using the weighing tool offered by the protocol, to compute manually to gain not just computation freedom but also to take advantage of local experts on weighings that could be considered more context-based than the rigid approach from the tool. Last, the communication of results was delivered with consultation from both policymakers and the researchers.

2.2.2 Gross list, core list, and evaluation of indicators. The gross list of indicators was defined using the framework of Vanloon et al. (2005). Note that indicators must be measurable, sensitive to variations, relevant to the case study, and related directly to the theme (Marchand et al., 2014).

The gross list of indicators was shortlisted to the core list of indicators most relevant to the case study, using predefined criteria including minimum one indicator per dimension: indicator for profitability and societal support, data availability, and large coverage of information (van Asselt et al., 2014). Experts also consider the compatibility and feasibility of indicators for assessing the sustainability of the coastal Mekong area.

For the specified case study, 60 indicators were proposed in the gross list based on literature and discussion with the expert group. A core list of 38 indicators was shortlisted using the mentioned criteria, which was discussed with the policymaker (Table AII). Sustainability limits of continuous indicators were set based on legal norms, policy targets, or best performance (Table AIII). Also, linear interpolation was used to convert data to the scale of 100 based on the three defined sustainability limits. Then, the core list of indicators was discussed with the policymaker to double-check on the relevance to the case study.

2.2.3 Sustainability limits. To evaluate whether or not an indicator value is sustainable, sustainability limits are compulsory. There are three levels of limits including nonsustainability, mid-sustainability, and sustainability. Limits were calculated based on available legal norms, policy targets, or best performing values. Interpolation and extrapolation were employed to calculate the required limits depending on available and retrievable limits. When only non-sustainability and sustainability limits were available, the mid-sustainability limit was calculated as the geometric mean of the two assuming lognormal distribution (van Asselt et al., 2014). Due to the inclusion of qualitative indicators, sustainability limits were only used for continuous indicators. For qualitative measured indicators using the MCA approach, the use of the scale between 1 "worst" to 10 "best" already implied worst and best limits, similar to non-sustainability and sustainability limits. Thus, assigning limits was not necessary for those indicators.

2.2.4 Data collection. Data were collected from both primary and secondary sources. To avoid bias from missing out stakeholder participation, this study incorporated both top-down (expert elicitation) and bottom-up (stakeholder) approaches (Binder et al., 2010). A total of 33 farmers from Thanh Phu commune and 25 farmers from Binh Dai commune were surveyed through a structured questionnaire in September 2018. Targeted local farmers must possess at least one year of farming experience and remain with IAA farming at the time of the survey. Two local extensionists and seven enumerators were appointed to assist the data-collecting process. Raw data were pre-processed at the end of the day to make sure information's correctness and to avoid missing data. Also, to simplify the scoring process, the researcher examined and adjusted scores from farmers in case of inconsistency and misclassified data.

2.2.5 Aggregation and weighting. Weighting is popular in conducting a sustainability assessment. Studies use weightings to address the importance of indicators, subthemes, themes, or dimensions. Weighting also serves to mitigate the conflict between global and 
JED

22,1

28

local applicability. Thus, weighting can be applied from indicator to dimension level, for example, SAFA, FAO (2014). Some assessment frameworks assigned maximum values to weighting at the indicator level, for example, IDEA, Zahm et al. (2008).

To comply with criterion 4 , this study conducted weighing and aggregation manually in a stepwise manner. First, weights were assigned by experts based on the aim and scope of this study, their understanding, and their judgment of how each component contributes to the final sustainability development at the community level. To simplify the weighting process, experts only weighted the importance of components at the theme level, which meant that all indicators were judged as equally important. A similar practice was performed in RISE 3.0, Grenz, Jan et al. (2016, p. 9), and SAFA, FAO (2014). The weights were constrained in a scale of 0-100 percent, of which the total weights of all themes equal 100 percent. Similar to the recommendation on influencing levels of sustainability components of Norman et al. (1998), experts' weightings were in favor of the social and economic dimension at the community level. Productivity, compatibility, and equity were equally important (score of 15 percent), while efficiency and durability were scored equally higher at 20 percent. For simplicity, each indicator under each theme was treated with equal importance. Second, before the aggregation, indicator values were converted to the scale of 100 against the predefined sustainability limits (van Asselt et al., 2014). In the case of qualitative indicators, data were amended to the scale of 100 accordingly. Third, data were converted to a same scale $(100$ points) to facilitate aggregation and comparison between indicators. Then, each theme score was calculated using the arithmetic mean of indicators predetermined under that specific theme.

The last step was the aggregation of theme scores with accordant weightings to calculate the final sustainability index. The calculation of overall sustainability index of each region (i.e., Binh Dai and Thanh Phu communes) can be formulated as:

$$
v(x)=\sum_{i=1}^{n} w_{i} v_{i}\left(x_{i}\right)
$$

where $v$ is a value aggregation function of score value $x_{i}, n$ is the number of themes, $w_{i}$ is the weight of each theme $i$, and $v_{i}\left(x_{i}\right)$ is the aggregation score of theme $i$. The value function $v_{i}(\cdot)$ gets normalized value between 0 and 100, and the weights $w_{i}$ get values between 0 and 100 percent, summing up to 100 percent.

\section{Results and discussion}

The overall sustainability scores were computed based on Eqn 1; thus, the scores of Binh Dai and Thanh Phu communes were 68 and 64, respectively. Comparing the sustainability of the rice-shrimp farming system of the two communes, Binh Dai commune was prominent in every aspect of the assessment. However, there was still plenty of room for improvement for both communes. Major improvements should be considered for productivity, efficiency, and equity themes, whilst minor improvements can be made for stability, durability, and compatibility themes (see Figure 4-10)

\subsection{Themes assessment}

3.1.1 Productivity. The average rice yield of Binh Dai and Thanh Phu was 5.4 tons/ha and 5.1 tons/ha, respectively. These were considerably higher than the average rice yield of Ben Tre province in 2017, which was 4.1 tons/ha; however, they were lower than the average rice yield of the Mekong River Delta in 2017, which was 5.6 tons/ha (GSO, 2017). This yield was possible due to climate-adapted crop scheduling (between August and December). Even though, the research areas belong to the brackish zone (salinity level $0.4-18 \%$ ), however, 

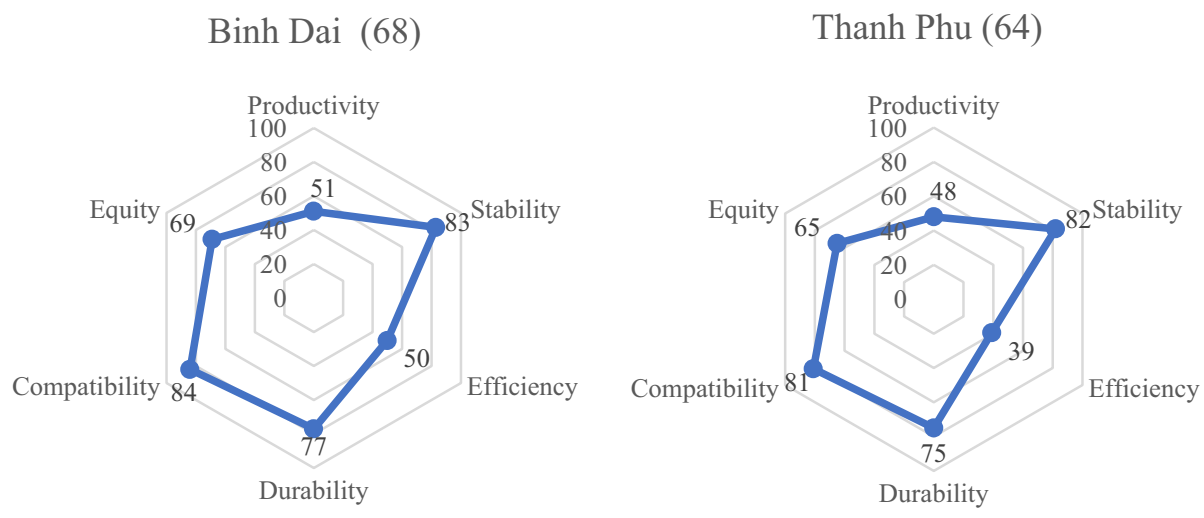

A climate
adaptive model

Note(s): Data are presented in percentage, the overall indices are in parentheses

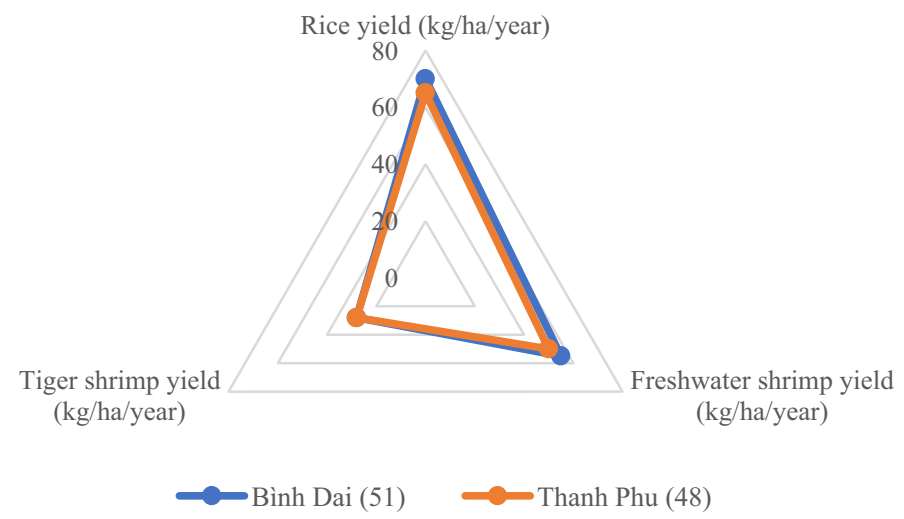

Note(s): Numbers in the legend's brackets are the overall sustainability index at theme level

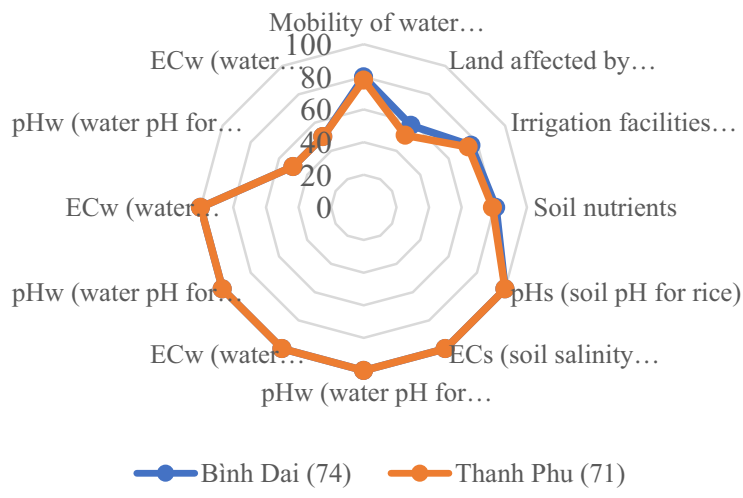

Note(s): Numbers in the legend's brackets are the overall sustainability index at theme level

Figure 6. Stability theme assessment of Binh Dai and Thanh Phu communes 
JED

22,1

30

Figure 7.

Durability theme assessment of Binh Dai and Thanh Phu communes

Figure 8.

Compatibility theme assessment of Binh Dai and Thanh Phu communes

Figure 9.

Average benefit cost structure of riceshrimp system

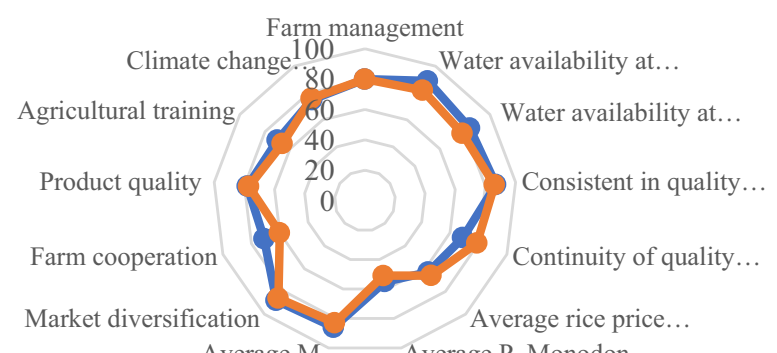

Average M.... Average P. Monodon...

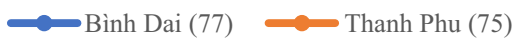

Note(s): Numbers in the legend's brackets are the overall sustainability index at theme level

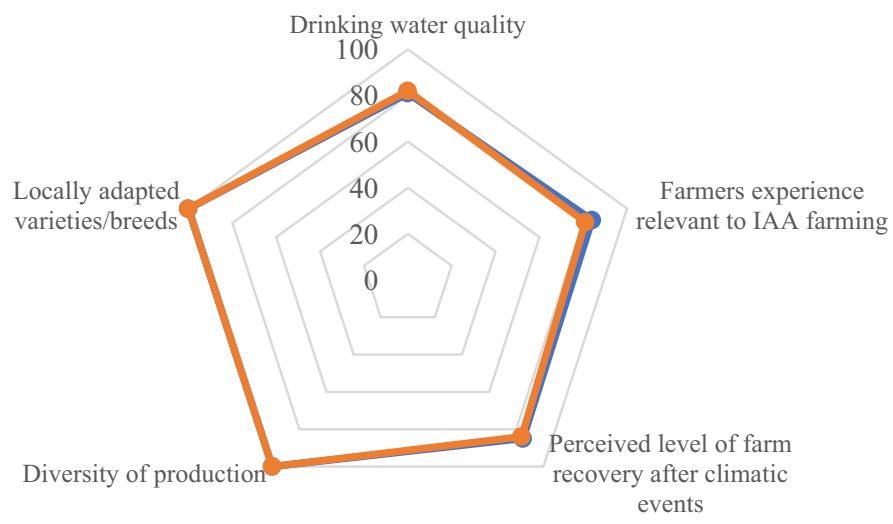

$\longrightarrow$ Binh Dai (90) $\quad \longrightarrow$ Thanh Phu (89)

Note(s): Numbers in the legend's brackets are the overall sustainability index at theme level

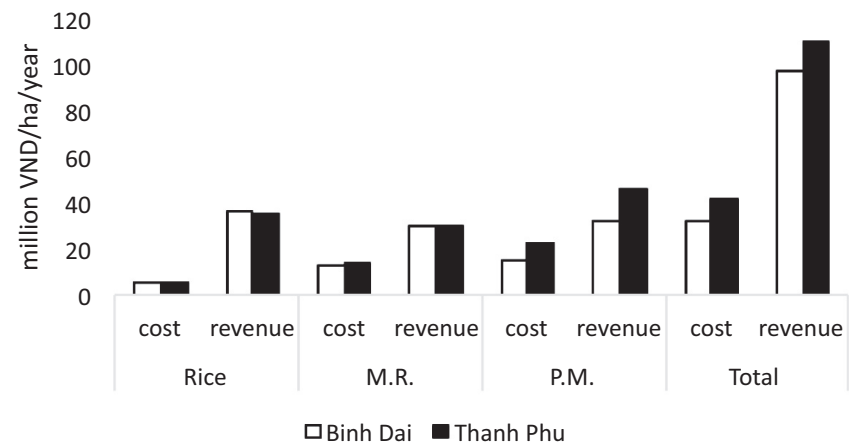




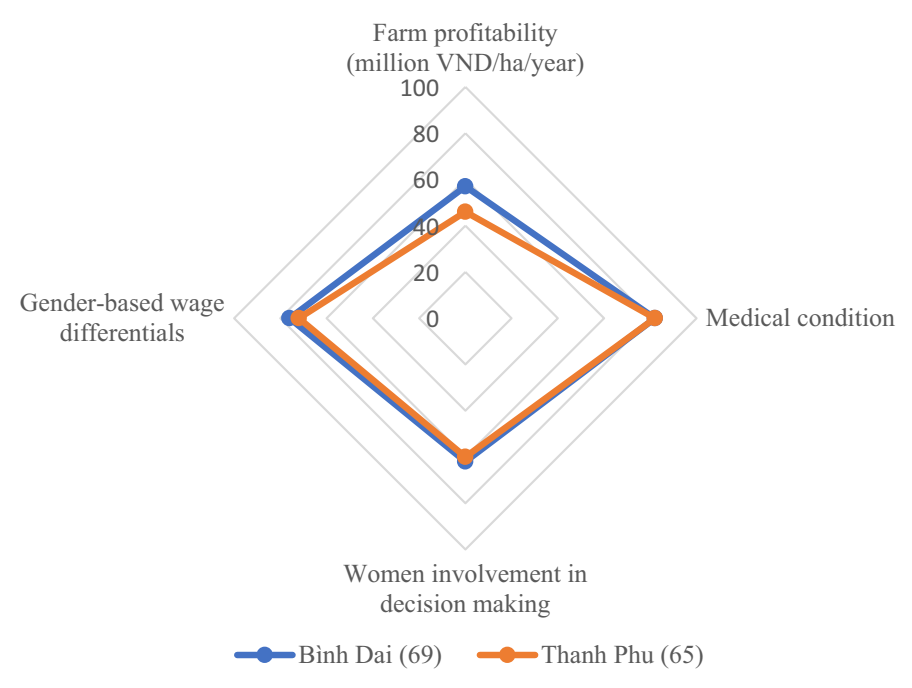

Note(s): Numbers in the legend's brackets are the overall sustainability index at theme level
A climate
adaptive model

31

Figure 10.

Equity theme assessment of Binh Dai and Thanh Phu communes

during the wet season, the residual salt from rice fields was flushed by rainfall and inflow of water. This created a suitable condition for rice-shrimp farming to be employed with a suitable $\mathrm{pH}$ and EC for soil and water (see Table AIII and Table AIV). Additionally, thanks to the promotion of local authority, the widespread use of drought- and salinity-tolerant varieties (e.g., OM 6162, Dai Thom 8, Nang Cha) helped to achieve high yields, thus adapt to climate change. Moreover, early rice harvesting in December helped to avoid prolonging the crop to the high salinity periods of late March and April (CCAFS, 2016). Low productivity scores were greatly affected by the low scores of freshwater shrimp and tiger shrimp yield. Numerous potential reasons for such low yields were identified as high stocking density, trash fish issues, and feed management (e.g., commercial feed, fresh feed from snail and trash fish, or mixed feed). Lan et al. (2006) reported that freshwater shrimp yield in the integrated farming system ranges between $400-1,680 \mathrm{~kg} / \mathrm{ha}$ at stocking densities of $2-6 \mathrm{SL} / \mathrm{m}^{2}$, while the stocking densities of local farmers ranged between $5-21 \mathrm{SL} / \mathrm{m}^{2}$. High stocking densities were the solution for farmers facing the trash fish issues. Rather than helping, high stocking densities worsened the situation, resulting in low survival rates due to lack of dissolved oxygen for shrimps and small shrimp sizes at the time of harvest. Similar to $M$. rosenbergii, P. monodon cultivation has had the same issues. For rotation crop in the case of P. Monodon, Truong (2017) suggested that the stocking densities of $7 \mathrm{SL} / \mathrm{m}^{2}$ would yield $360-400 \mathrm{~kg} / \mathrm{ha} /$ crop. Thus, the productivity of shrimp cultivation in Thanh Phu and Binh Dai required proper attention to max out its potential (See Table AV)

3.1.2 Stability. The research areas in Thanh Phu and Binh Dai communes were both brackish water zones. Salinity intrusion emerges as a key factor in affecting the stability of farming systems in the areas. Similar $\mathrm{pH}$ and EC patterns were observed between the two communes. Water and soil EC were low at the beginning of the rice crop at $0.4 \mathrm{dS} / \mathrm{m}$ and $0.27 \mathrm{dS} / \mathrm{m}$, respectively, and increased gradually to $25.1 \mathrm{dS} / \mathrm{m}$ and $6.57 \mathrm{dS} / \mathrm{m}$, respectively, at the beginning of the P. monodon crop in March; however, thanks to the leaching effect of rainfall at the beginning of the rainy season in June, water and soil EC tended to decrease afterward (Hoa et al., 2016). Besides, the pattern of water and soil $\mathrm{pH}$ was evaluated as 
JED

22,1

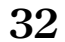

suitable for rice-shrimp farming. Water $\mathrm{pH}$ in the canal varied from neutral to mild alkaline (7.21-8.46), suitable for rice-shrimp farming. Soil $\mathrm{pH}$ ranged from mildly acidic to nearly neutral (5.34-6.3). In the rice and $M$. rosenbergii simultaneous crop (July to December), the $\mathrm{pH}$ value of soil ranged from mild acidic to nearly neutral (5.34-6.19) (Hoa et al., 2016). The pHand EC of water and soil increased drastically during the P. monodon crop (March to July) due to farmers accessing an influx of saline water to perform the alternate shrimp culture. Ben Tre province was also identified as most affected by drought (CCAFS, 2016). The severe drought, due to low water discharge from upstream of the Mekong river and the rising sea levels, resulted in the decrease of groundwater levels and the more extensive salinity intrusion. Several measures were taken in response to climate change. From 2011 until now, asystem of dikes and sluice gates was built and maintained to control salinity intrusion (Can, 2015). Thus, the mobility of water and irrigation facilities was highly appreciated by local farmers in terms of climate adaptation. However, Ben Tre district's DARD reported that salinity levels, for the first time in 2016, reached its peak two months earlier, instead of March and April, and intruded beyond the dikes further inland and also extended its duration in the dry season (CCAFS, 2016). Therefore, climate monitoring and early warning systems play an important role in mitigating the negative impacts of climate change, improving the stability of the riceshrimp model in the Mekong Delta.

3.1.3 Efficiency. Efficiency was measured by the monetary efficiency of the system. The average monetary efficiency of Binh Dai and Thanh Phu communes was 3.48 and 2.83, respectively. The average benefit-cost ratio $(\mathrm{BCR})$ of rice, freshwater shrimp, and tiger shrimp were 9.85, 2.4, and 3.22, respectively. The BCR of rice was significantly higher than expected. This was achievable for two reasons. First, to grow shrimps, farmers must adopt the organic practice of using no pesticide or insecticide. Therefore, the output rice was considered organic and resulted in a higher price and demand. As observed, Thanh Phu organic rice was bought by companies at the price of 8,500 VND/kg. Compared to 2012-2013, the price of organic rice in Thanh Phu doubled with stable outputs. Furthermore, the National Office of Intellectual Property, under the Ministry of Science and Technology, has granted "lúa sach Thạnh Phúh (clean rice Thanh Phu) trademark to local farmers since 2016. This granted evidence on the sustainable path of the current farming system. However, farmers in this study are still at their beginning to adopt the practice. Hence, the quality of product outputs (i.e., rice and shrimps) still requires much improvement to meet the standard of the market to achieve a higher price. For that reason, the current output price, let us say rice of $6,500 \mathrm{VND} / \mathrm{kg}$ (Binh Dai) and 6,800 VND/kg (Thanh Phu) in this study, signaled the potential for improvement to meet the market standard to obtain higher prices.

Second, the effluent waste of the shrimp culture left a nutrient-rich environment ready for the rice crop; thus, fertilizer cost can be saved. Additionally, farmers' long-lasting experience was dedicated to growing rice rather than shrimps, which resulted in better rice yields than shrimp yields. Indeed, the yield, as well as quality of shrimps, remained a problem in the study sample, which was the reason why farmers can only sell, let us say, $M$. rosenbergii of $145,606 \mathrm{VND} / \mathrm{kg}$ (Binh Dai) and 141,600 VND/kg (Thanh Phu), while the market price for organic $M$. rosenbergii was $250,000-300,000 \mathrm{VND} / \mathrm{kg}$ reported by local extension agents. In comparison with other sustainability themes, there is plenty of room for improvement of the efficiency of the rice-shrimp system. Especially farmers and the local authority should pay more attention to ameliorating the efficiency of shrimp cultivation.

3.1.4 Durability. The durability of the rice-shrimp farming system in Thanh Phu and Binh Dai communes derived partly from the practice of no chemical pesticide or insecticide. Instead, farmers used biological insecticides from herbs and probiotic products in response to pest stress. Additionally, the sludge, which contained microorganisms, algae, leftover shrimp feeds, and shrimp manure settling down at the bottom of the trench, after shrimp harvest, was pumped to the surface of the rice field. This layer of the sludge discharge, after being dried in 
the sun, becomes a nutrient-rich and sustainable soil for rice. All farming practices together helped to facilitate farm management peculiar to Thanh Phu and Binh Dai. Thus, the average farm management score of 7.96 for both communes reflected farmers' perception of a fairly high level of ease and convenience for the current system. Also, the cooperation between farmers, and between farmers and local extensions, made the system more durable. Via agricultural trainings, local extensions helped to transfer knowledge and experiences among farmers. Local extensions applied an innovative approach of frequent river water measurement, which indicated water quality (i.e., $\mathrm{pH}$, salinity level) and suitable timing to inform farmers when to draw water into the field. Along with preventing intrusion of saline, the dike system enables water being always available at every stage of the rice cultivation, including sowing and flowering stage. Regarding rice varieties, due to the impact of salinity intrusion and drought, farmers adopted short-cycle varieties integrated with salinity- and drought-tolerant attributes (e.g., OM 6161, Dai thom 8, Nang Cha). Thanks to the combined short and long-term cycles based on climate change, farmers were able to produce better rice yields in comparison to the intensive rice system. However, the problem of the rice-shrimp system emerged from shrimp, not rice. However, the quality and continuity of shrimp postlarvae were stable, provided from trusted hatcheries such as Minh Phu and the Research Institute for Aquaculture No.2. The problem associated with shrimp cultivation could be stocking densities and trash fish issues, resulting in the harvested shrimp sizes varying greatly $(37 \pm 15 \mathrm{~S} / \mathrm{kg})$ for $P$. monodon and $(32 \pm 2 \mathrm{~S} / \mathrm{kg})$ for $M$. rosenbergii, which directly affected farmers' revenues due to big differences in prices for smaller sizes. Overall, the riceshrimp farming system in Binh Dai was more sustainable than that of Thanh Phu in term of durability.

3.1.5 Compatibility. Since the early 1980s, the culture of rice-shrimp farming has developed (Phuong et al., 2006). Since then, the farming system has evolved to cope with changes in the Mekong Delta. The winter-spring crop has shifted to earlier periods from December-March to August-December in response to the shift in the rainfall pattern in the Mekong Delta. Through various severe losses and damages from numerous typhoons and tropical depressions as an impact of climate change, farmers' climate change awareness was strengthened. Thus, along with their past farming experience, farmers in Binh Dai and Thanh Phu have had a better head-start on IAA farming systems due to their relevant skills and knowledge. Indeed, farmers in Binh Dai and Thanh Phu, respectively, have had an average of 8.42 and 8.12 years of experience related to rice-shrimp farming. Comparing the most experienced local farmers, the majority of farmers of Binh Dai and Thanh Phu have accomplished around 8-10 years and 7-10 years of experience, respectively. This could be an inarguable advantage for local farmers to cope with unpredictable climatic events. Similar to the finding of Poelma (2018) in researching the transition of rice-shrimp farming in Kien Giang, rice-shrimp farmers were affected least by changing climatic conditions, whereas rice or shrimp farmers witnessed a lower level of resilience to the impacts of climatic conditions. This study confirmed a perceived positive recovery of rice-shrimp farming against climate change events of Binh Dai (85) and Thanh Phu (84). By definition, compatibility also means sustaining the surrounding environment such as water contamination and loss of biodiversity. The biodiversity aspect of rice-shrimp farming was also investigated with two indicators borrowed from FAO (2014), including production diversity and locally adapted varieties/breeds. Since the rice-shrimp farming model in the research area has been the combination of the alternative and integrative cultures, the nature of the farming model augments crops to be diversified and highly suitable to the goal of sustaining the diversified state of production, which, in turn, has received the maximum score. To cope with climate change (i.e., salinity intrusion), local farmers adopted locally adapted short-cycle varieties integrated with salinity- and drought-tolerant attributes (e.g., OM 6161, Dai Thom 8, Nang Cha) in full, which enhanced the genetic diversity to preserve the biodiversity and the saving 
JED

22,1

34

of indigenous seeds and breeds. Regarding drinking water quality, the situation was recorded similar to other provinces of the Mekong Delta where drinking water was mostly derived from rainfalls and the underground water (Poelma, 2018). The drinking water in Ben Tre, especially in Thanh Phu and Binh Dai Districts, was exposed to 1-2 dS/m degree of salinity level in both self-drilled wells and protected water pipeline (DWRM, 2016), whereas the total dissolved solids (TDS) level of drinkable water must remain below $1.56 \mathrm{dS} / \mathrm{m}$ (or 1,000 mg/l) according to the national technical regulation QCVN 01-11:2018/BYT on the quality of clean water used for domestic purposes. This was not too high above the limit, and was also a good use of rainwater; local farmers still maintained sufficient levels of drinkable water, which contributed to the relatively high scores of drinking water quality of Binh Dai (81) and Thanh $\mathrm{Phu}$ (82). For the mentioned reasons, the farming model was considered highly compatible with the research area.

3.1.6 Equity. The overall equity scores of Binh Dai and Thanh Phu were low due to low scores on farms' profitability and women's involvement in decision-making about agricultural activities. The increasing magnitude of average costs for rice, $M$. rosenbergii, and P. monodon was $4.74 \pm 3.71,12.36 \pm 4.32$, and $14.75 \pm 11.65$ million $\mathrm{VND} /$ ha/year, and $5.25 \pm 3.23,13.25 \pm 1.84$, and $22.27 \pm 21.33$ million VND/ha/year for Binh Dai and Thanh Phu, respectively. Apparently, the cost of P. Monodon varied greatly between the two communes, especially in Thanh Phu. Farmers in Binh Dai performed better in cost control and also in revenue. The average revenue for rice, freshwater shrimp, and tiger shrimp was $35.72 \pm 8.42$, $29.93 \pm 10.64$, and $31.45 \pm 23.49$ million VND/ha/year, and $34.98 \pm 8.91,29.17 \pm 12.59$, and $45.79 \pm 30.94$ million VND/ha/year, for Binh Dai and Thanh Phu, respectively.

The medical condition of farmers in the rice-shrimp system between the two communes was highly evaluated due to the adoption of no pesticides, which closely resembled organic practices. Indeed, local authorities are spending efforts to register organic trademarks for the rice and shrimp products of Binh Dai and Thanh Phu. This is very promising to the future productivity of the areas when the price of organic products is 2-3 times higher along with the increasing demand of consumers for safe food. Regarding the gender perspective for agricultural activities, similar to the report of Grassi et al. (2017), the rice-shrimp farming system was labor-intensive due to limited machinery involvement; therefore, family labors accounted for the majority of the activities. Besides hired labor, exchange labor-a costsaving and reciprocal practice (mostly between friends and relatives) — was considered an advantage of the local farming system. The gender division of labor remained aligned with gender roles, in which men were assigned to heavy tasks, while women were mostly assigned to time-consuming light tasks. Because of this perception, women's labor inputs are often considered insignificant to that of men. As a result, women's wages are lower: women receive an average of $120000 \mathrm{VND} /$ day (US\$5.18) for weeding, harvesting, and shrimp-feeding, while men are paid an average of $140000 \mathrm{VND} /$ day (US\$6.04) for rice hauling, mud removing, and shrimp harvesting. Also, women's lack of access to productive resources, such as technology, training, and credit, was likely a factor that made their voices in major household's agricultural decisions undervalued or neglected (Grassi et al., 2017). This study found a similar pattern of women's involvement in decision-making about agricultural activities. The mean scores of women-involvement indices of Binh Dai and Thanh Phu were 6.13 and 6.24, which explained why equity scores of Binh Dai and Thanh Phu were low at 69 and 65, respectively.

\section{Conclusion}

Agricultural sustainability of the rice-shrimp farming system in Binh Dai and Thanh Phu was assessed by both qualitative and quantitative indicators under six sustainability categories, namely, productivity, stability, efficiency, durability, compatibility, and equity. This study conducted the assessment transparently in a stepwise manner with predefined 
criteria to ensure the aim and scope of the research topic. The combination of the assessment protocol of van Asselt et al. (2014), the assessment framework of Vanloon et al. (2005), and the MCA methodology provided a flexible and holistic approach to assess the sustainability level of agricultural systems (e.g., rice-shrimp system). Results from this study shed light on the above-average sustainability levels of rice-shrimp farming systems in Binh Dai and Thanh Phu communes - coastal areas of Ben Tre province, which was severely impacted by climate change. In terms of compatibility, durability, and stability assessment themes, the current rice-shrimp model in local areas showed the potential to cope with climate change. However, major areas for improvements are productivity, efficiency, and equity categories. Several factors could potentially contribute to the low performance of the productivity and efficiency of the rice-shrimp system, including shrimp stocking densities or dissolved oxygen (DO). concentration, trash fish issues, and feed management, which require in-depth technical supports from experts and local extensionists to max out the potential of the local rice-shrimp farming system. Productivity and efficiency of the farming system could be dramatically improved via different mentioned measures, despite current obvious barriers. It should be noted that the farming model might just be at its starting point, and with the help of current cutting-edge technologies and climate adaptive knowledge, foreseeable improvements are surely expectable. Hence, this paper urges the development of the rice-shrimp farming system in the Mekong Delta as a resort to incoming unpredictable climatic events.

\section{Policy implications}

To increase the adaptive capacities and resilience of the current system, proper government intervention is needed to be in place. Experts recommended the promotion of climate-smart agriculture, such as real-time early warning system, climate adaptive rice varieties, changes in cropping schedule and duration, and climate-related farming knowledge dissemination (CCAFS, 2016). The application of technology in climate-smart agriculture yields positive and potential initial results. Diversification of channels for knowledge dissemination and technology transfer via pilot model, extension training programs, and cooperation programs between farmers and other stakeholders enhances farmers' ability to adapt to climate change in the short- and long-term.

Regarding water management, to cope with the decreasing upstream flows, it is necessary to apply water-saving technologies in upstream provinces (e.g., An Giang, Dong Thap, Tien Giang) to secure sufficient water flow for coastal downstream provinces (e.g., Ben Tre, Tra Vinh). Furthermore, a long-term intervention of upstream flow management requires cooperation between countries occupying upstream of the Mekong river.

\section{Declaration}

Data availability statement: The data set used and/or analyzed during the current study are available from the corresponding author on reasonable request.

Funding: Part of this research was generously funded under grant number KHCN-TNBDT/14-19/C20.

\section{List of abbreviations}

IAA system Integrated agriculture-aquaculture (IAA) farming systems are defined as systems sharing resources between aquaculture with agriculture.

P. monodon Penaeus monodon, commonly known as the giant tiger prawn or Asian tiger shrimp.

L. vannamei Litopenaeus vannamei also known as Pacific white shrimp or white-legged shrimp.

$\begin{array}{r}\text { A climate } \\ \text { adaptive model } \\ \mathbf{3 5} \\ \hline\end{array}$ 
Macrobrachium rosenbergii, also known as the giant river prawn or giant freshwater prawn.

\section{References}

Ali, A.M.S. (2006), "Rice to shrimp: and use/land cover changes and soil degradation in Southwestern Bangladesh", Land Use Policy, Vol. 23 No. 4, pp. 421-435, doi: 10.1016/j.landusepol.2005.02.001.

Allan, G.L. and Maguire, G.B. (1992), "Effects of pH and salinity on survival, growth and osmoregulation in penaeus monodon fabricius", Aquaculture, Vol. 107 No. 1, pp. 33-47, doi: 10. 1016/0044-8486(92)90048-P.

Binder, C.R., Feola, G. and Steinberger, J.K. (2010), "Considering the normative, systemic and procedural dimensions in indicator-based sustainability assessments in agriculture”, Environmental Impact Assessment Review, Vol. 30 No. 2, pp. 71-81, doi: 10.1016/j.eiar.2009.06.002.

Can, N. (2015), "Adaptation to salinity intrusion: an aconomic assessment of diversified farming systems in saline affected area of coastal ben tre province of the Mekong Delta, Vietnam1", Paper presented at the International Symposium on Current Agricultural Environmental Issues in Pacific Rim Nations and their Countermeasures - II, Saga University, Saga, Japan, https:// www.researchgate.net/publication/275152179_Adaptation_to_Salinity_Intrusion_An_Economic_ Assessment_of_Diversified_Farming_Systems_in_Saline_Affected_Area_of_Coastal_Ben_Tre_ Province_of_the_Mekong_Delta_Vietnam1.

CCAFS. (2016), Assessment Report: The Drought and Salinity Intrusion in the Mekong River Delta of Vietnam, CGIAR Research Program on Climate Change, Agriculture and Food Security (CCAFS), Hanoi, Vietnam, Retrieved from: https://hdl.handle.net/10568/75633.

Chen, S.M. and Chen, J.C. (2003), "Effects of pH on survival, growth, molting and feeding of giant freshwater prawn Macrobrachium rosenbergii", Aquaculture, Vol. 218 No. 1, pp. 613-623. doi: 10.1016/S0044-8486(02)00265-X.

De Mey, K., D’Haene, K., Marchand, F., Meul, M. and Lauwers, L. (2011), "Learning through stakeholder involvement in the implementation of MOTIFS: an integrated assessment model for sustainable farming in Flanders", International Journal of Agricultural Sustainability, Vol. 9 No. 2, pp. 350-363, doi: 10.1080/14735903.2011.582355.

Dobermann, A. and Fairhurst, T. (2000), Rice: Nutrient Disorders and Nutrient Management, PPI/PPIC, Singapore and IRRI, Philippines, Retrieved from: http://books.irri.org/9810427425_content.pdf.

DWRM. (2016), Khảo sát tình hình sủ dụng nước của bà con tại vùng đang bị mặn tại hai huyện Thạnh Phú và Ba Tri tỉnh Bến Tre. Retrieved from: http://dwrm.gov.vn/index.php? language $=$ vi\&nv $=$ news\&op $=$ Hoat-dong-cua-Cuc-Tin-lien-quan/Nuoc-tu-thuy-dien-Canh-Hongchua-ve-toi-Campuchia-490010/10/2019.

FAO. (2014), Sustainability Assessment of Food and Agriculture Systems (SAFA): Guidelines, Version 3.0, Food and Agricultural Organization of the United Nations, Rome.

Gasso, V., Oudshoorn, F.W., de Olde, E. and Sørensen, C.A.G. (2015), "Generic sustainability assessment themes and the role of context: the case of Danish maize for German biogas", Ecological Indicators, Vol. 49, pp. 143-153, doi: 10.1016/j.ecolind.2014.10.008.

Grassi, F., Paris, T.R. and Truong, T.N.C. (2017), Rice-rice and Rice-Shrimp Production. A Gender Perspective on Labour, Time Use and Access to Technologies and Services in Southern Viet Nam, FAO, Rome, Retrieved from: http://www.fao.org/3/a-i7277e.pdf.

GSO. (2016). Statistical Year Book, Ha Noi, Retrieved from: https://www.gso.gov.vn/default.aspx? tabid $=512$ \&idmid $=5 \& I t e m I D=18531$.

GSO. (2017). Statistical Yearbook, Hanoi, Retrieved from: https://www.gso.gov.vn/default.aspx? tabid $=512 \&$ idmid $=5 \&$ ItemID $=18940$.

Hoa, N.M., Guong, V.T., Tung, T.S. and Giang, N.H. (2016), "Salinisation of soil and water on agricultural and aquacultural systems in Binh Dai district, Ben Tre province", Can Tho University Journal, Vol. 42, pp. 40-49, doi: 10.22144/ctu.jvn.2016.019. 
IMHEN. (2010), Climate Change and Impact in Vietnam, Science and technology publisher, Hanoi, Retrieved from: http://dcc.gov.vn/kien-thuc/998/Sach:-Bien-doi-khi-hau-va-tac-dong-o-VietNam.html.

IRRI. (2015), Steps to Successful Rice Production, IRRI, Philippines, Retrieved from: http:// knowledgebank.irri.org/images/docs/12-Steps-Required-for-Successful-Rice-Production.pdf.

Jan, G., Raphael, M., Michael, S., Firesenai, S., Susanne, S., Christian, T. and Rebekka, W. (2016), Rise 3.0 - Manual Sustainability Themes and Indicators, Bern University of Applied Sciences, Zollikofen, Switzerland, Retrieved from: www.rise.hafl.bfh.ch.

Kihoro, J., Bosco, N.J. and Murage, H. (2013), "Suitability analysis for rice growing sites using a multicriteria evaluation and GIS approach in great Mwea region, Kenya", SpringerPlus, Vol. 2 No. 1, pp. 265, doi: 10.1186/2193-1801-2-265.

Lan, L.M., Micha, J.C., Long, D.N. and Yen, P.T. (2006), "Effect of densities and culture systems on growth, survival, yield, and economic return of freshwater prawn, Macrobrachium rosenbergii farming in the rice field in the Mekong Delta, Vietnam”, Journal of Applied Aquaculture, Vol. 18 No. 1, pp. 43-62, doi: 10.1300/J028v18n01_03.

Leigh, C., Hiep, L.H., Stewart-Koster, B., Vien, D.M., Condon, J., Sang, N.V., Sammut, J. and Burford, M.A. (2017), "Concurrent rice-shrimp-crab farming systems in the Mekong Delta: are conditions (sub) optimal for crop production and survival?", Aquaculture Research, Vol. 48 No. 10, pp. 5251-5262.

Loc, H.H., Diep, N.T.H., Can, N.T., Irvine, K.N. and Shimizu, Y. (2017), "Integrated evaluation of ecosystem services in prawn-rice rotational crops, Vietnam" Ecosystem services, Vol. 26, pp. 377-387, doi: 10.1016/j.ecoser.2016.04.007.

Luu, L.T. (2002), Sustainable Aquaculture for Poverty Alleviation (SAPA): A New Rural Development Strategy for Viet Nam. Part II, FAO Aquaculture Newsletter (FAO), Rome, Italy.

Marchand, F., Debruyne, L., Triste, L., Gerrard, C., Padel, S. and Lauwers, L. (2014), "Key characteristics for tool choice in indicator-based sustainability assessment at farm level", Ecology and Society, Vol. 19 No. 3.

MARD. (2016), Tóm Tắt Đánh Giá Điều Kiện Xã Hội Khu Vực (RSA), The ministry of agriculture and rural development, Ha Noi, Retrieved from: www.bentre.gov.vn.

Motoh, H. (1981), Studies on the Fisheries Biology of the Giant Tiger Prawn, Penaeus monodon in the Philippines (0115-4710), Aquaculture Department, Southeast Asian Fisheries Development Center, Philippines, Retrieved from: https://repository.seafdec.org.ph/handle/10862/860.

Ness, B., Urbel_Piirsalu, E., Anderberg, S. and Olsson, L. (2007). "Categorising tools for sustainability assessment”, Ecological Economics, 60, 498-508, doi: 10.1016/j.ecolecon.2006.07.023.

Nguyen, K.A.T., Jolly, C.M., Bui, C.N.P.T. and Le, T.T.H. (2016), "Aquaculture and poverty alleviation in ben Tre province, Vietnam", Aquaculture Economics and Management, Vol. 20 No. 1, pp. 82-108, doi: 10.1080/13657305.2016.1124938.

Nhan, D.K., Phong, L.T., Verdegem, M.J.C., Duong, L.T., Bosma, R.H. and Little, D.C. (2007), "Integrated freshwater aquaculture, crop and livestock production in the Mekong Delta, Vietnam: determinants and the role of the pond", Agricultural Systems, Vol. 94 No. 2, pp. 445-458, doi: 10.1016/j.agsy.2006.11.017.

Nho, N.T., Khắc Thường, T. and Diệp, L.M. (2006), Kỹ Thuạt Nuôi Giáp Xác, NXB Nông Nghiệp (or Agriculture), Ho Chi Minh.

Norman, D., Janke, R., Freyenberger, S., Schurle, B. and Kok, H. (1998), Defining and Implementing Sustainable Agriculture. Kansas Sustainable Agriculture Series, Paper, 1, available at: http:// www.soc.iastate.edu/Sapp/soc235susag.pdf.

OECD. (2001), Environmental Indicators for Agriculture - Vol. 3: Methods and Results, OECD, Paris, Retrieved from: https://www.oecd.org/tad/sustainable-agriculture/40680869.pdf.

People Committee of Thanh Phu District. (2018), Report on the Integration of Land Use Plan for 2018, Thanh Phu District - Ben Tre Province, People's Comittee, Ben Tre. A climate
adaptive model 
JED

22,1

38

Phuong, N.T., Hai, T.N., Hien, T.T.T., Van Bui, T., Son, V.N., Morooka, Y., Fukuda, Y. and Wilder, M.N. (2006), "Current status of freshwater prawn culture in Vietnam and the development and transfer of seed production technology", Fisheries Science, Vol. 72 No. 1, pp. 1-12. doi: 10. 1111/j.1444-2906.2006.01109.x.

Poelma, T.F. (2018), Transitioning to Rice-Shrimp Farming in Kien Giang, Vietnam Determining Rural Household Resilience to Changing Climatic Conditions. (Master), Utretcht University, Utrecht, Retrieved from https://dspace.library.uu.n1/handle/1874/368049.

Quach, A.V., Murray, F. and Morrison-Saunders, A. (2017), "The vulnerability of shrimp farming income to climate change events: a case study in Ca Mau, Vietnam", International Journal of Climate Change Strategies and Management, Vol. 9 No. 2, pp. 261-280.

Renaud, F.G., Le, T.T.H., Lindener, C., Guong, V.T. and Sebesvari, Z. (2015), "Resilience and shifts in agro-ecosystems facing increasing sea-level rise and salinity intrusion in Ben Tre Province, Mekong Delta”, Climatic Change, Vol. 133 No. 1, pp. 69-84, doi: 10.1007/s10584-014-1113-4.

Talukder, B., Saifuzzaman, M. and vanLoon, G.W. (2016), "Sustainability of agricultural systems in the coastal zone of Bangladesh", Renewable Agriculture and Food Systems, Vol. 31 No. 2, pp. 148-165, doi: 10.1017/S1742170515000095.

Truong, H.M. (2017), "Evaluating technical and financial aspects of shrimp production in rotation shrimp (Penaeus monodon) farm system in Ca Mau province", Can Tho University Journal of Science, Vol. 50, pp. 133-139.

Van Asselt, E.D., Van Bussel, L.G.J., Van der Voet, H., Van der Heijden, G.W.A.M., Tromp, S.O., Rijgersberg, H., Van Evert, F., Van Wagenberg, C.P.A. and Van der Fels-Klerx, H.J. (2014), "A protocol for evaluating the sustainability of agri-food production systems - a case study on potato production in peri-urban agriculture in the Netherlands", Ecological Indicators, Vol. 43, pp. 315-321, doi: 10.1016/j.ecolind.2014.02.027.

Vanloon, G.W., Patil, S.G. and Hugar, L.B. (2005), Agricultural Sustainability: Strategies for Assessment, Sage Publications, New Delhi.

WCED. (1987), Our Common Future. Report of the World Commission on Environment and Development, The United Nations, Oslo, Retrieved from: www.un-documents.net/our-commonfuture.pdf.

World Bank. (2010), The Social Dimensions of Adaptation to Climate Change in Vietnam. World Bank, Washington, DC, USA, Retrieved from: http:/documents.worldbank.org/curated/en/ 955101468326176513/pdf/589030NWP0EACC10Box353823B01public1.pdf.

Zahm, F., Viaux, P., Vilain, L., Girardin, P. and Mouchet, C. (2008), “Assessing farm sustainability with the IDEA method - from the concept of agriculture sustainability to case studies on farms", Sustainable Development, Vol. 16, pp. 271-281. 


\begin{tabular}{|c|c|}
\hline Name of indicator & Measureme \\
\hline $\begin{array}{l}\text { Productivity } \\
\text { A. Rice }\end{array}$ & \\
\hline $\begin{array}{l}\text { 1. Productivity: grain yield } \\
\text { B. Giant river shrimp (or } M \text {. Rosenbergii) }\end{array}$ & $\mathrm{kg} / \mathrm{ha} / \mathrm{year}$ \\
\hline $\begin{array}{l}\text { 2. Productivity: shrimp yield } \\
\text { C. Giant tiger shrimp (or P. Monodon) }\end{array}$ & $\mathrm{kg} / \mathrm{ha} /$ year \\
\hline 3. Productivity: yield & $\mathrm{kg} / \mathrm{ha} / \mathrm{year}$ \\
\hline
\end{tabular}

Stability

A. Landscape

4. Mobility of water on land

5. Land surface exposure to saline water

6. Land affected by drought in dry season

7. Irrigation facilities of the land

B. Soil health

8. Soil physical properties ${ }^{a}$

9. Soil texture ${ }^{a}$

10. Bulk density ${ }^{\mathrm{a}}$

11. Soil chemical properties ${ }^{\mathrm{a}}$

12. Organic material ${ }^{\mathrm{a}}$

13. $\mathrm{pH}$

14. EC

C. Soil nutrients

15. Digested NPK ${ }^{\mathrm{a}}$

16. Chrome $(\mathrm{Cr})^{\mathrm{a}}$

17. Copper $(\mathrm{Cu})^{\mathrm{a}}$

18. Arsenic (As) ${ }^{\mathrm{a}}$

19. Cadmium (Cd) ${ }^{\mathrm{a}}$

20. Mercury $(\mathrm{Hg})^{\mathrm{a}}$

D. Water

21. Salinity level of surface water

22. $\mathrm{pH}$

23. EC

24. $\mathrm{DO}^{\mathrm{a}}$

E. Other issues

25. Withdraw of upstream water

26. Drying of river $^{\mathrm{a}}$

27. Stability of embankment $\mathrm{t}^{\mathrm{a}}$

Efficiency

28. Monetary efficiency

29. Overall energy efficiency ${ }^{a}$

Durability

A. Resistance to pest stress

30. Chemical response to pest stress ${ }^{\mathrm{a}}$

31. Farm management

B. Freshwater availability

32. Water availability at sowing stage of rice

33. Water availability at flowering stage of rice

C. Seed

34. Consistent in quality of rice varieties

\section{Weight Data source}

15

Questionnaire survey

Questionnaire survey

Questionnaire survey

15

Range from 1 to 10

Range from 1 to 10

Range from 1 to 10

Range from 1 to 10

$\mathrm{dS} / \mathrm{m}$

$\%$

$\mathrm{dS} / \mathrm{m}$

ppm

$\$$ outputs $/ \$$ inputs

Energy outputs/

energy inputs

Range from 1 to 10

Range from 1 to 10

Range from 1 to 10

Range from 1 to 10

Range from 1 to 10
Questionnaire survey

Government document

Questionnaire survey

Questionnaire survey

Literature review

Literature review

Government document

Literature review

Field observation

Field observation

20 Questionnaire survey

20

Questionnaire survey

Questionnaire survey

Table AII.

Themes for assessing the sustainability in coastal IAA systems

Questionnaire survey

(continued) and specific indicators accompanying the case of rice-shrimp farming 
Name of indicator

35. Continuity of quality shrimp seed

D. Economics

36. Product price

37. Market diversification

38. Farm cooperation

39. Product quality

E. Agricultural knowledge

40. Agricultural training

41. Soil test before and after production cycle $^{\mathrm{a}}$

42. Climate change awareness

Compatibility

A. Human

43. Illness from drinking water ${ }^{\mathrm{a}}$

44. Drinking water quality

45. Farmers' experience relevant to IAA

farming

46. Perceived level of farm recovery after

climatic events

B. Biophysical compatibility

47. Diversity of production

48. Locally adapted varieties/breeds

49. Overall biodiversity condition:

percentage of non-crop area ${ }^{a}$

50 . Overall biodiversity condition: crop

richness $^{\mathrm{a}}$

Equity

\section{A. Education}

51. Educational status of farmer ${ }^{\mathrm{a}}$

52. Educational status of farmers' male

children $^{\text {a }}$

53. Educational status of farmers' female

children A

B. Economic

54. Farm profitability

55. Farmer income ${ }^{\mathrm{a}}$

C. Livelihood diversity other than agriculture 56. Road networks (establishing farm roads and access roads) ${ }^{\mathrm{a}}$

D. Health

57. Medical condition

58. Sanitation facilities ${ }^{\mathrm{a}}$

E. Gender

59. Women's involvement in decisionmaking about agricultural activities 60. Gender-based wage differentials

Note(s): ${ }^{a}$ not applicable for the case study

Table AII.
Measurement Weight Data source

Range from 1 to 10

$\mathrm{VND} / \mathrm{kg}$

Questionnaire survey

Range from 1 to 10

Range from 1 to 10

Range from 1 to 10

Range from 1 to 10

Range from 1 to 10

Range from 1 to 10

Range from 1 to 10

Range from 1 to 10

Range from 1 to 10

Range from 1 to 10

Range from 1 to 10

Range from 1 to 10 $\%$

Number of crops

Questionnaire survey

15

Questionnaire survey

Field observation

Field observation

Field observation

Questionnaire survey

15

Questionnaire survey

Years to school

Years to school

Years to school

VND/ha/year

$\mathrm{VND} /$ ha/year

Range from 1 to 10

Questionnaire survey

Range from 1 to 10

$\%$

Range from 1 to 10

Questionnaire survey

Field observation

Questionnaire survey

Questionnaire survey

Range from 1 to 10 


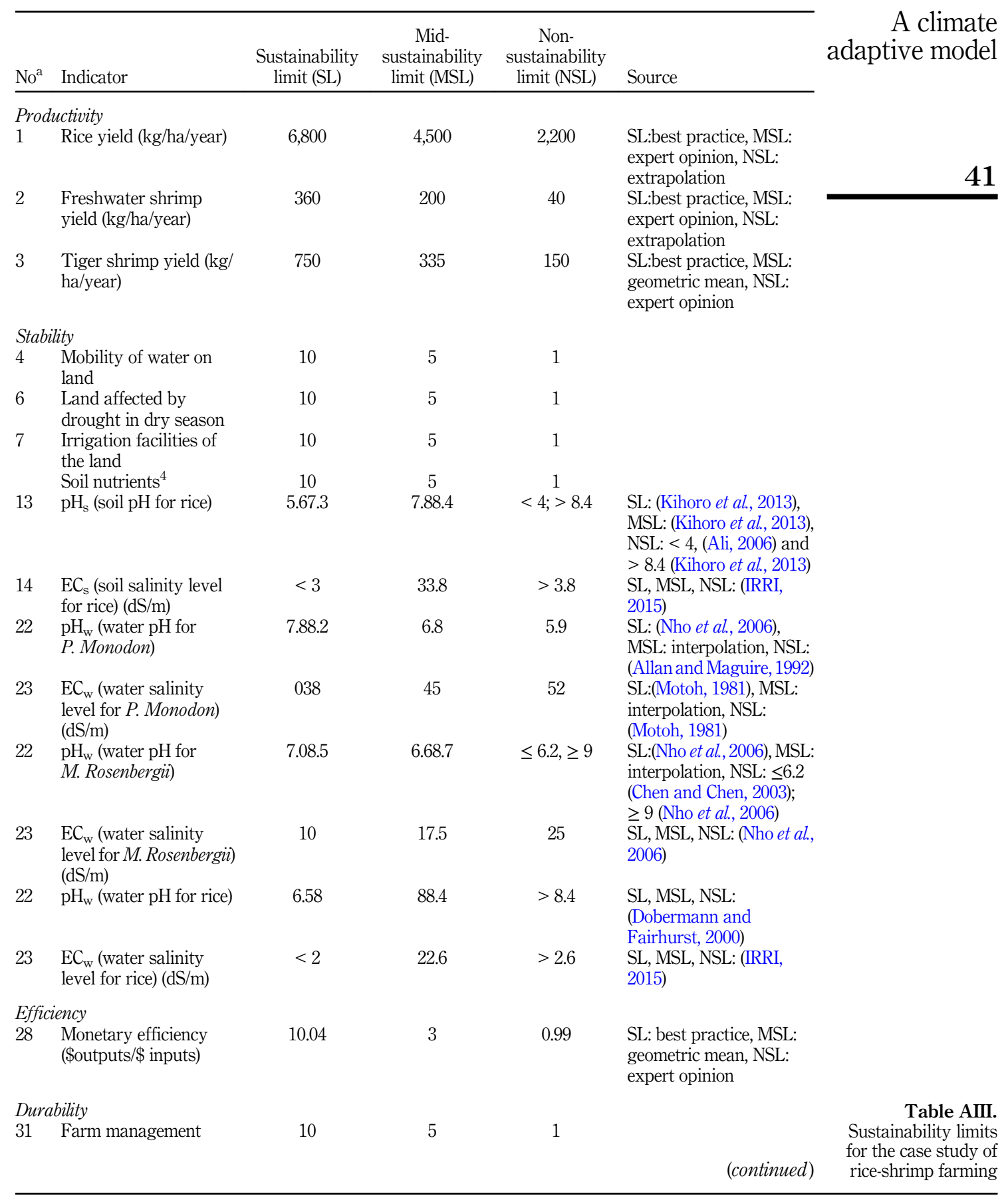




\begin{tabular}{|c|c|c|c|c|c|}
\hline $\mathrm{No}^{\mathrm{a}}$ & Indicator & $\begin{array}{l}\text { Sustainability } \\
\text { limit (SL) }\end{array}$ & $\begin{array}{c}\text { Mid- } \\
\text { sustainability } \\
\text { limit (MSL) }\end{array}$ & $\begin{array}{c}\text { Non- } \\
\text { sustainability } \\
\text { limit (NSL) }\end{array}$ & Source \\
\hline 32 & $\begin{array}{l}\text { Water availability at } \\
\text { sowing stage of rice }\end{array}$ & 10 & 5 & 1 & \multirow{12}{*}{$\begin{array}{l}\text { SL: best price obtained }{ }^{3} \text {, } \\
\text { MSL: geometric mean, } \\
\text { NSL: expert opinion } \\
\text { SL: best price obtained }{ }^{3} \text {, } \\
\text { MSL: geometric mean, } \\
\text { NSL: min price to } \\
\text { breakeven } \\
\text { SL: best price obtained, } \\
\text { MSL: geometric mean, } \\
\text { NSL: min price to } \\
\text { breakeven }\end{array}$} \\
\hline 33 & $\begin{array}{l}\text { Water availability at } \\
\text { flowering stage of rice }\end{array}$ & 10 & 5 & 1 & \\
\hline 34 & $\begin{array}{l}\text { Consistent in quality of } \\
\text { rice varieties }\end{array}$ & 10 & 5 & 1 & \\
\hline 35 & $\begin{array}{l}\text { Continuity of quality } \\
\text { shrimp postlarvae }\end{array}$ & 10 & 5 & 1 & \\
\hline 36 & $\begin{array}{l}\text { Average rice price } \\
\text { (VND/kg) }\end{array}$ & 9,000 & 5,600 & 3,500 & \\
\hline & $\begin{array}{l}\text { Average } P . \text { Monodon } \\
\text { price (VND } / \mathrm{kg} \text { ) }\end{array}$ & 220,000 & 144,000 & 24,000 & \\
\hline & $\begin{array}{l}\text { Average } M . \text { Rosenbergï } \\
\text { price (VND/kg) }\end{array}$ & 200,000 & 100,000 & 50,000 & \\
\hline 37 & Market diversification $^{1}$ & 10 & 5 & 1 & \\
\hline 38 & Farm cooperation ${ }^{2}$ & 10 & 5 & 1 & \\
\hline 39 & Product quality & 10 & 5 & 1 & \\
\hline 40 & Agricultural training & 10 & 5 & 1 & \\
\hline 41 & $\begin{array}{l}\text { Climate change } \\
\text { awareness }\end{array}$ & 10 & 5 & 1 & \\
\hline \multicolumn{6}{|c|}{ Compatibility } \\
\hline 44 & Drinking water quality & 10 & 5 & 1 & \\
\hline 45 & $\begin{array}{l}\text { Farmers' experience } \\
\text { relevant to IAA farming }\end{array}$ & 10 & 5 & 1 & \\
\hline 46 & $\begin{array}{l}\text { Perceived level of farm } \\
\text { recovery after climatic } \\
\text { events }\end{array}$ & 10 & 5 & 1 & \multirow{7}{*}{$\begin{array}{l}\text { SL: best profit obtained }{ }^{3} \text {, } \\
\text { MSL: average profit }{ }^{3} \text {, } \\
\text { NSL: no profit. }\end{array}$} \\
\hline 47 & Diversity of production & 10 & 5 & 1 & \\
\hline 48 & $\begin{array}{l}\text { Locally adapted } \\
\text { varieties/breeds }\end{array}$ & 10 & 5 & 1 & \\
\hline \multicolumn{6}{|c|}{ Equity } \\
\hline 54 & $\begin{array}{l}\text { Farm profitability } \\
\text { (million VND/ha/year) }\end{array}$ & 132 & 62 & 0 & \\
\hline 57 & Medical condition & 10 & 5 & 1 & \\
\hline 59 & $\begin{array}{l}\text { Women's involvement } \\
\text { in decision-making } \\
\text { about agricultural } \\
\text { activities }\end{array}$ & 10 & 5 & 1 & \\
\hline 60 & $\begin{array}{l}\text { Gender-based wage } \\
\text { differentials }\end{array}$ & 10 & 5 & 1 & \\
\hline
\end{tabular}

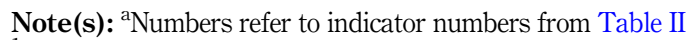

${ }^{1}$ Market diversification is the average of market diversification for shrimp and rice

${ }^{2}$ Farm cooperation is the average of the cooperation between farmers and between farmers and other stakeholders ${ }^{3}$ Data were calculated and round-up from the research data

${ }^{4} \mathrm{~A}$ qualitative statement of "whether or not soil nutrients were suitable for rice-shrimp farming"; answer varied

Table AIII. from "absolutely not - 0" to "absolutely suitable - 10" 


\begin{tabular}{|c|c|c|c|c|c|c|c|c|c|}
\hline \multirow{2}{*}{ Indicators } & \multirow{2}{*}{ Mean } & \multicolumn{3}{|c|}{ Binh Dai $(n=33)$} & \multirow{2}{*}{ Mean } & \multicolumn{2}{|c|}{ Thanh Phu $(n=25)$} & \multirow{2}{*}{ Max } & \multirow{2}{*}{$\begin{array}{l}\text { A climate } \\
\text { adaptive model }\end{array}$} \\
\hline & & Std. dev. & & VIIdX & & & & & \\
\hline Rice yield (kg/ha/year) & $5,403.03$ & 738.02 & 4,200 & 6,800 & 5,188 & 718.98 & 4,300 & 6,500 & \\
\hline $\begin{array}{l}\text { Freshwater shrimp } \\
\text { yield (kg/ha/year) }\end{array}$ & 216.67 & 59.86 & 100 & 320 & 201.68 & 63.38 & 100 & 360 & \\
\hline $\begin{array}{l}\text { Tiger shrimp yield } \\
\text { (kg/ha/year) }\end{array}$ & 259.33 & 197.11 & 25 & 750 & 274.72 & 186.55 & 88 & 714 & 43 \\
\hline $\begin{array}{l}\text { Mobility of water on } \\
\text { land }\end{array}$ & 8 & 1.63 & 5 & 10 & 7.76 & 2.38 & 0 & 10 & \\
\hline $\begin{array}{l}\text { Land affected by } \\
\text { drought in dry season }\end{array}$ & 5.75 & 2.47 & 0 & 10 & 5.08 & 2.62 & 0 & 10 & \\
\hline $\begin{array}{l}\text { Irrigation facilities of } \\
\text { the land }\end{array}$ & 7.60 & 2.31 & 2 & 10 & 7.44 & 2.46 & 0 & 10 & \\
\hline Soil nutrients & 8.06 & 1.65 & 5 & 10 & 7.92 & 2.36 & 0 & 10 & \\
\hline $\mathrm{pH}_{\mathrm{s}}(\text { soil } \mathrm{pH} \text { for rice })^{1}$ & 5.84 & N/A & 5.39 & 6.3 & 5.84 & N/A & 5.39 & 6.3 & \\
\hline $\begin{array}{l}\mathrm{EC}_{\mathrm{S}} \text { (soil salinity level } \\
\text { for rice) }(\mathrm{dS} / \mathrm{m})^{1}\end{array}$ & 1.73 & N/A & 0.27 & 3.2 & 1.73 & N/A & 0.27 & 3.2 & \\
\hline $\begin{array}{l}\mathrm{pH}_{\mathrm{w}}(\text { water } \mathrm{pH} \text { for } \\
\text { P. Monodon })^{1}\end{array}$ & 7.75 & N/A & 7.5 & 8 & 7.75 & N/A & 7.5 & 8 & \\
\hline $\begin{array}{l}\mathrm{EC}_{\mathrm{w}} \text { (water salinity } \\
\text { level for P. Monodon) } \\
(\mathrm{dS} / \mathrm{m})^{1}\end{array}$ & 16.5 & N/A & 8 & 25 & 16.5 & N/A & 8 & 25 & \\
\hline $\begin{array}{l}\mathrm{pH}_{\mathrm{w}}(\text { water } \mathrm{pH} \text { for } \\
M \text {. Rosenbergii) }\end{array}$ & 7.83 & N/A & 7.21 & 8.46 & 7.83 & N/A & 7.21 & 8.46 & \\
\hline $\begin{array}{l}\mathrm{EC}_{\mathrm{w}} \text { (water salinity } \\
\text { level for } M \text {. Rosenbergii) } \\
(\mathrm{dS} / \mathrm{m})^{1}\end{array}$ & 1.43 & N/A & 0.4 & 2.46 & 1.43 & N/A & 0.4 & 2.46 & \\
\hline $\mathrm{pH}_{\mathrm{w}}$ (water $\mathrm{pH}$ for rice) ${ }^{1}$ & 7.83 & N/A & 7.21 & 8.46 & 7.83 & N/A & 7.21 & 8.46 & \\
\hline $\begin{array}{l}\mathrm{EC}_{\mathrm{w}} \text { (water salinity } \\
\text { level for rice) }(\mathrm{dS} / \mathrm{m})^{1}\end{array}$ & 1.43 & N/A & 0.4 & 2.46 & 1.43 & N/A & 0.4 & 2.46 & \\
\hline $\begin{array}{l}\text { Monetary efficiency } \\
\text { (\$outputs/\$ inputs) }\end{array}$ & 3.48 & 1.28 & 0.49 & 6.52 & 2.83 & 1.10 & 1.07 & 4.83 & \\
\hline Farm management & 7.96 & 1.64 & 4 & 10 & 7.96 & 1.13 & 6 & 10 & \\
\hline $\begin{array}{l}\text { Water availability at } \\
\text { sowing stage of rice }\end{array}$ & 8.93 & 1.19 & 5 & 10 & 8.24 & 2.33 & 2 & 10 & \\
\hline $\begin{array}{l}\text { Water availability at } \\
\text { flowering stage of rice }\end{array}$ & 8.39 & 1.47 & 5 & 10 & 7.88 & 2.33 & 2 & 10 & \\
\hline $\begin{array}{l}\text { Consistent in quality of } \\
\text { rice varieties }\end{array}$ & 8.72 & 1.48 & 4 & 10 & 8.6 & 1.22 & 5 & 10 & \\
\hline $\begin{array}{l}\text { Continuity of quality } \\
\text { shrimp postlarvae }\end{array}$ & 6.90 & 2.55 & 2 & 10 & 7.88 & 1.66 & 4 & 10 & \\
\hline $\begin{array}{l}\text { Average rice price } \\
\text { (VND/kg) }\end{array}$ & $6,506.06$ & 932.04 & 5,000 & 8,800 & 6,832 & $1,560.90$ & 3,000 & 10,000 & \\
\hline $\begin{array}{l}\text { Average P. Monodon } \\
\text { price (VND/kg) }\end{array}$ & $145,606.1$ & $38,319.33$ & 70,000 & 220,000 & 141,600 & $25,768.2$ & 100,000 & 180,000 & \\
\hline $\begin{array}{l}\text { Average } \\
\text { M. Rosenbergii price } \\
\text { (VND/kg) }\end{array}$ & $171,212.1$ & $13,406.52$ & 140,000 & 200,000 & 166,000 & $10,801.23$ & 140,000 & 180,000 & \\
\hline Market diversification & 8.80 & 1.17 & 6 & 10 & 8.62 & 1.17 & 7 & 10 & \\
\hline Farm cooperation & 7.13 & 2.58 & 0 & 10 & 6 & 3.32 & 0 & 10 & \\
\hline Product quality & 7.84 & 1.66 & 5 & 10 & 7.72 & 1.59 & 5 & 10 & \\
\hline Agricultural training & 7.03 & 2.70 & 1 & 10 & 6.64 & 2.44 & 2 & 10 & \\
\hline $\begin{array}{l}\text { Climate change } \\
\text { awareness }\end{array}$ & 7.54 & 1.92 & 3 & 10 & 7.6 & 2.16 & 3 & 10 & Table AIV. \\
\hline Drinking water quality & 8.14 & 1.43 & 4 & 10 & 8.24 & 1.33 & 6 & $\begin{array}{c}10 \\
\text { tinued) }\end{array}$ & $\begin{array}{r}\text { Descriptive statistics of } \\
\text { sustainability } \\
\text { indicators }\end{array}$ \\
\hline
\end{tabular}




\begin{tabular}{|c|c|c|c|c|c|c|c|c|}
\hline \multirow[b]{2}{*}{ Indicators } & \multirow[b]{2}{*}{ Mean } & \multicolumn{3}{|c|}{$\operatorname{Binh}$ Dai $(n=33)$} & \multicolumn{4}{|c|}{ Thanh Phu $(n=25)$} \\
\hline & & Std. dev. & Min & Max & Mean & Std. dev. & Min & $\operatorname{Max}$ \\
\hline $\begin{array}{l}\text { Farmers experience } \\
\text { relevant to IAA } \\
\text { farming }\end{array}$ & 8.42 & 1.43 & 5 & 10 & 8.12 & 1.48 & 6 & 10 \\
\hline $\begin{array}{l}\text { Perceived level of farm } \\
\text { recovery after climatic } \\
\text { events }\end{array}$ & 8.5 & 1.19 & 6 & 10 & 8.39 & 1.2 & 6 & 10 \\
\hline Diversity of production & 10 & 0 & 10 & 10 & 10 & 0 & 10 & 10 \\
\hline $\begin{array}{l}\text { Locally adapted } \\
\text { varieties/breeds }\end{array}$ & 10 & 0 & 10 & 10 & 10 & 0 & 10 & 10 \\
\hline $\begin{array}{l}\text { Farm profitability } \\
\text { (million VND/ha/year) }\end{array}$ & 65.24 & 20.13 & 29.54 & 104.47 & 69.17 & 36.10 & 4 & 125.4 \\
\hline Medical condition & 8.24 & 1.39 & 5 & 10 & 8.24 & 1.23 & 6 & 10 \\
\hline $\begin{array}{l}\text { Women's involvement } \\
\text { in decision-making } \\
\text { about agricultural } \\
\text { activities }\end{array}$ & 6.24 & 2.56 & 0 & 10 & 6 & 2.48 & 2 & 10 \\
\hline Gender-based wage & 7.69 & 1.51 & 5 & 10 & 7.16 & 1.84 & 4 & 10 \\
\hline
\end{tabular}

Table AIV. differentials

Note(s): ${ }^{1}$ Data were obtained from the study of for the research areas

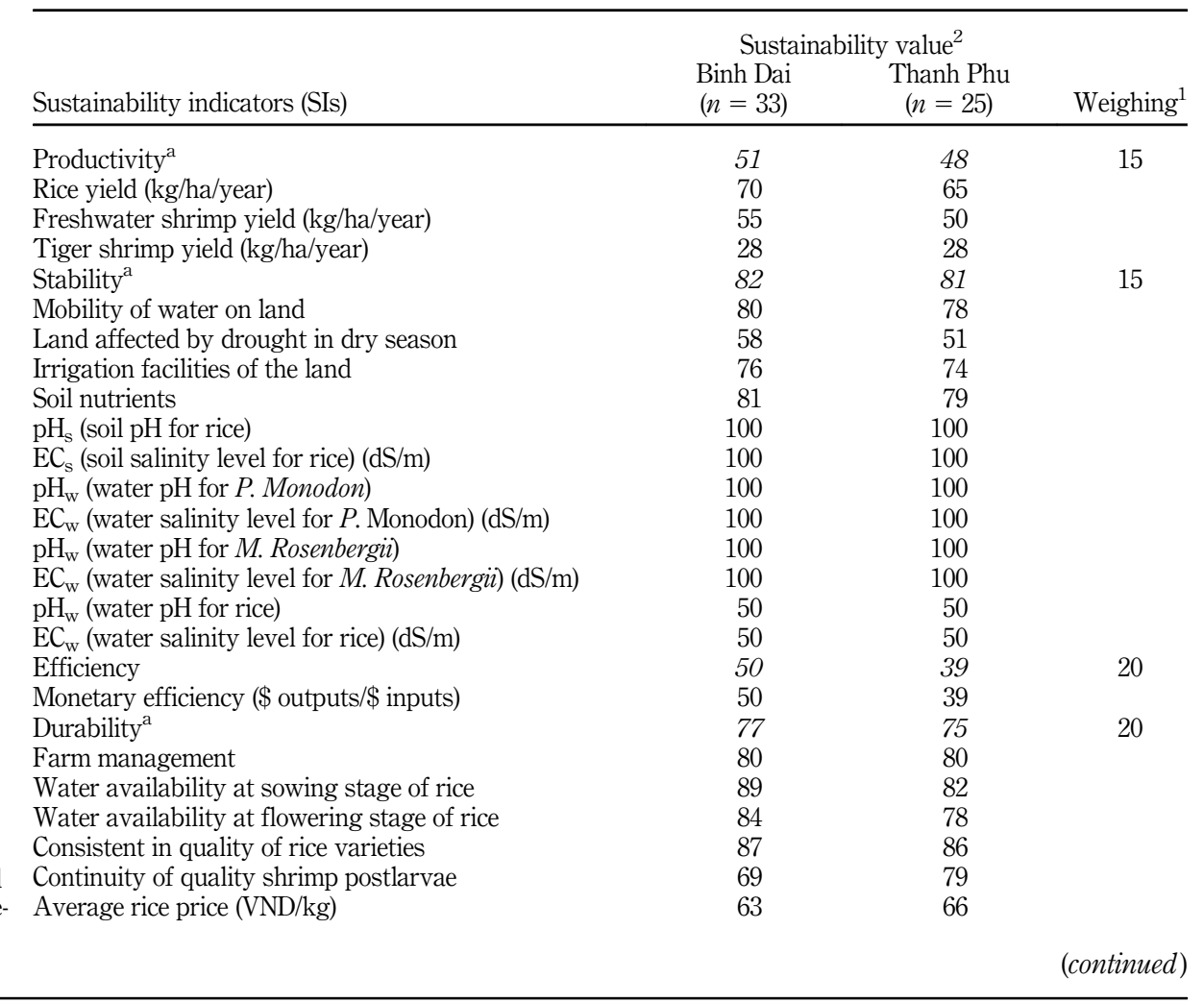

Table AV.

Sustainability indicators' values and overall indexes of riceshrimp integrated farming system 


\begin{tabular}{|c|c|c|c|c|}
\hline Sustainability indicators (SIs) & $\begin{array}{l}\text { Susta } \\
\text { Binh Dai } \\
(n=33)\end{array}$ & $\begin{array}{l}\text { y value }{ }^{2} \\
\text { Thanh Phu } \\
(n=25)\end{array}$ & Weighing $^{1}$ & $\begin{array}{r}\text { A climate } \\
\text { adaptive model }\end{array}$ \\
\hline Average P. Monodon price (VND/kg) & 55 & 51 & & \\
\hline Average $M$. Rosenbergii price (VND/kg) & 86 & 83 & & \\
\hline Market diversification & 88 & 86 & & \\
\hline Farm cooperation & 71 & 60 & & 45 \\
\hline Product quality & 78 & 77 & & \\
\hline Agricultural training & 70 & 66 & & \\
\hline Climate change awareness & 75 & 76 & & \\
\hline Compatibility $^{\mathrm{a}}$ & 84 & 81 & 15 & \\
\hline Drinking water quality & 81 & 82 & & \\
\hline Farmers experience relevant to IAA farming & 84 & 81 & & \\
\hline Perceived level of farm recovery after climatic events & 85 & 84 & & \\
\hline Diversity of production & 100 & 100 & & \\
\hline Locally adapted varieties/breeds & 100 & 100 & & \\
\hline Equity $^{\mathrm{a}}$ & 69 & 65 & 15 & \\
\hline Farm profitability (million VND/ha/year) & 57 & 46 & & \\
\hline Medical condition & 82 & 82 & & \\
\hline $\begin{array}{l}\text { Women's involvement in decision-making about } \\
\text { agricultural activities }\end{array}$ & 62 & 60 & & \\
\hline Gender-based wage differentials & 76 & 72 & & \\
\hline Overall index ${ }^{\mathrm{b}}$ & 68 & 64 & & \\
\hline
\end{tabular}

Note(s): ${ }^{1}$ Weighing obtained from expert consultation

${ }^{2}$ Data were normalized to the scale of 100 and rounded up

a Rounded average of indicators' values in the same category. ${ }^{\text {b}}$ Rounded calculated percentage using Eqn 1

Table AV.

\section{Corresponding author}

Huy Duc Dang can be contacted at: ddhuy@hcmuaf.edu.vn

For instructions on how to order reprints of this article, please visit our website:

www.emeraldgrouppublishing.com/licensing/reprints.htm

Or contact us for further details: permissions@emeraldinsight.com 